\title{
ANALISIS SISTEM PEMIKIRAN GENDER BERBASIS KEAGAMAAN DI PESANTREN JAWA TIMUR
}

\author{
Mustari Bosra \\ Universitas Negeri Makassar, Indonesia \\ E-mail: bosra_mustari@yahoo.com \\ Umiarso \\ Universitas Muhammadiyah Malang, Indonesia \\ E-mail: umiarso@umm.ac.id \\ Asyraf Isyraqi bin Jamil \\ Universiti Malaya, Kuala Lumpur, Malaysia \\ E-mail: isyraqi@um.edu.my
}

\begin{abstract}
This research concentrates on the religiousbased gender framework within the pesantren education system by which pesantren has an institutional vision to empower women and naturally participates in developing gender discourse with Islamic religious nuance. This research was conducted in East Java by taking the site of Pesantren Nurul Islam Antirogo, Pesantren Al-Falah Karangharjo Jember, and Pesantren Annuqayah GulukGuluk Sumenep. This research found that those pesantrens carried out reconstruction through theological-philosophical awareness that was designed from the dialogic process of reinterpretative religious normative texts with reality. The emergence of this awareness led the pesantren to direct their education system to feel egalitarian, non-discriminatory, and nonsubordinate towards women inside and outside the pesantren. The axiology of the pesantren education system lead to the normative value of the unity of humanity. The realization of the education system ended up on peace values whether in the cultural, social, or even religious domains.
\end{abstract}

Keywords: Pesantren; gender; women empowerment.

\section{Pendahuluan}

Pesantren sebagai diskursus akademik melahirkan berbagai karya intelektual mulai dari aspek kurikulum, kepemimpinan kiai, sistem kependidikan multikultural, jejaring sosial, teknologi, pola 
madrasah diniyah, sistem tarekat, bahkan pola pemberdayaan masyarakat yang dilakukan pesantren. ${ }^{1}$ Hal ini menandakan bahwa masyarakat mengakui kontribusi pesantren sebagai suatu subkultur. Terlebih lagi pesantren terus mengalami transformasi sehingga memunculkan beragam kategori, yaitu: pesantren buruh pabrik, pesantren anak jalanan, pesantren mahasiswa, pesantren lingkungan, pesantren entrepreneur, atau pesantren moral. ${ }^{2}$ Diskursus pesantren sebagai subkultur akan semakin menarik ketika dikaitkan dengan pemberdayaan perempuan dan pengarusutamaan gender.

Upaya pengarusutamaan gender di Indonesia sesungguhnya telah dilakukan secara masif dan sistemik seperti yang dilakukan

${ }^{1}$ Muazza et al., "Education in Indonesia Islamic Boarding Schools: Voices on Curriculum and Radicalism, Teacher, and Facilities," The Islamic Quarterly, Vol. 62, No. 4 (2018), 507-536; Yanwar Pribadi, "Kiai in Madura: Their Roles in Local Politics in Indonesia," American Journal of Islamic Social Sciences, Vol. 29, No. 3 (2012), 1-22; Mahmud Arif, "Multiculturalism of Pesantren Kyai: A Study of Kyai's Perspective on Multicultural Issues and Their Actualization at Pesantren Sunni Darussalam and al-Imdad Yogyakarta Indonesia," International Journal of Education and Research, Vol. 4 No. 10 (2016), 253-272; Khojir, "The Pesantren Network in Samarinda," Jurnal Pendidikan Islam, Vol. 5, No. 2 (2016), 213-233; Wahyuddin Halim, "Young Islamic Preachers on Facebook: Pesantren As'adiyah and its Engagement with Social Media," Indonesia and The Malay World, Vol. 46, No. 134 (2018), 44-60; Zumrotul Mukaffa, "Madrasah Diniyah Sebagai Pola Diseminasi Islam Moderat di Pesantren Mahasiswa Darussalam Keputih Surabaya," Jurnal Pendidikan Agama Islam, Vol. 6, No. 1 (2018), 127-156; Munawar Rahmat, "Kiai Hasan Ulama Mursyid Tarekat Shaththariah As a Pioneer of Modern Pesantren," Jurnal Pendidikan Islam, Vol. 7, No. 1 (2018), 1 22; Agusti et al., "The Role of Islamic Boarding School on the Economic Empowerment of the Society: a Case Study at Islamic Boarding School Salafiyah Syafi'iyah Banyuputih Situbondo," International Journal of Research in Humanities and Social Studies, Vol. 6, No. 3 (2019), 53-62.

2 Ali Mas'ud et al., "Evolution and Orientation of Islamic Education in Indonesia and Malaysia", Journal of Indonesian Islam, Vol. 13, No. 1 (2019), 21-49; Imam Bawani et al., Pesantren Burub Pabrik: Pemberdayaan Burub Pabrik Berbasis Pendidikan Pesantren (Yogyakarta: LkiS, 2011); Abdl. Chayyi Fanani, Pesantren Anak Jalanan (Surabaya: Alpha, 2008); Florian Pohl, Islamic Education and the Public Sphere: Today's Pesantren in Indonesia (New York: Waxmann, 2009), 117; Anna M. Gade, "Tradition and Sentiment in Indonesian Environmental Islam," Worldviews: Global Religions, Culture, and Ecology, Vol. 16, No. 3 (2012), 263-285; Hasbi Indra, "Pesantren and Entrepreneurship Education," Edukasi: Jurnal Penelitian Pendidikan Agama dan Keagamaan, Vol. 17, No. 2 (2019), 188-198; Juju Saepudin, "Pesantren Darut Taubah dan Pekerja Seks Komersial Saritem Kota Bandung," Analisa: Journal of Social Science and Religion, Vol. 22, No. 2 (2015), 201209. 
organisasi keagamaan Nasyiatul Aisyiyah (Muhammadiyah) ${ }^{3}$ atau Fatayat (Nahdlatul Ulama). ${ }^{4}$ Demikian juga yang dilakukan oleh Pesantren Nurul Islam Jember, Pesantren Aqidah Usymuni Madura, dan Pesantren Darut Tauhid Cirebon, di mana usaha pengarusutamaan gender telah menjadi bagian dari sistem kependidikan. Tiga pesantren ini merekonstruksi diri menjadi pesantren gender melalui aspek kepemimpinan, kurikulum, sistem nilai yang berkelindan, dan jejaring kerja pesantren. ${ }^{5}$ Karenanya muncul pesantren-pesantren yang merekonstruksi visi kelembagaan demi terbukanya peran mereka terhadap diskursus pengembangan civil society, multikulturalisme, atau pemberdayaan perempuan, seperti yang disinyalir dalam tulisan Sirry, ${ }^{6}$ Hoon, ${ }^{7}$ dan Srimulyani. ${ }^{8}$

Pesantren gender tersebut juga mempunyai budaya demokratis terhadap perkembangan intelektualitas perempuan dan tidak tabu terhadap konstruksi pemikiran perempuan. Proses rekonstruksi pesantren ini tidak lepas dari sistem pemikiran gender berbasis keagamaan yang mereka yakini, bersamaan dengan adanya usaha perempuan membangun otoritas keagamaan berbasis komunitas yang mampu menekan munculnya interpretasi teks-teks keagamaan (al-Qur'ān, Hadīth, dan kitab kuning) tanpa bias gender;' dan adanya perempuan progresif dengan preferensi simbolis yang

3 Claire-Marie Hafner, "Model of Achievement: Muslim Girls and Religious Authority in a Modernist Islamic Boarding School In Indonesia," Asian Studies Review, Vol. 40, No. 4 (2016), 564-582.

4 Monika Arnez, "Empowering Women Through Islam: Fatayat NU Between Tradition and Change," Journal of Islamic Studies, Vol. 21, No. 1 (2010), 59-88.

5 Abd. Halim Soebahar, "Pesantren Gender: Konstruksi Baru Basis Pemberdayaan Perempuan," al-Adalab: Jurnal Kajian Keislaman dan Kemasyarakatan, Vol. 5, No. 2 (2002), 1-8.

${ }^{6}$ Mun'im Sirry, "The Public Expression of Traditional Islam: The Pesantren and Civil Society in Post-Suharto Indonesia," The Muslim World, Vol. 100, No. 1 (2010), 60-77.

7 Chang-Yau Hoon, "Putting Religion into Multiculturalism: Conceptualising Religious Multiculturalism in Indonesia," Asian Studies Review, Vol. 41, No. 3 (2017), 476-493.

${ }^{8}$ Eka Srimulyani, "Muslim Women and Education in Indonesia: The Pondok Pesantren Experience," Asia Pacific Journal of Education, Vol. 27, No. 1 (2007), 8599.

9 Nor Ismah, "Destabilising Male Domination: Building Community-Based Authority among Indonesia Female Ulama," Asian Studies Review, Vol. 40, No. 4 (2017), 491-509. 
memperkuat wacana tentang kemampuan nya untuk menjadi ulama, ${ }^{10}$ atau yang mempengaruhi pengadopsian kebajikan moralitas seperti kewajiban perempuan memakai jilbab. ${ }^{11}$ Karenanya, pesantren memfilterisasi diskursus gender dengan menyelaraskannya dengan nilai normatif al-Qur'ān dan Sunnah atau mengupayakan penafsiran kembali dan memahami ulang teks-teks keagamaan seperti teks hadīth misoginis melalui pendekatan historis, sosiologis, dan antropologis. ${ }^{12}$

Berdasarkan hal tersebut, artikel ini menganalisa proses rekonstruksi pesantren di Jawa Timur dalam mengarusutamakan gender sebagai basis pemberdayaan perempuan. Fokus analisisnya terletak pada kerangka nilai-nilai normatif pemikiran gender yang bernuansa keagamaan sebagai basis teologis dan fiosofis pemberdayaan perempuan. Fokus tulisaan ini adalah pada tiga pesantren besar di Jawa Timur, yaitu Pesantren Nurul Islam Antirogo (selanjutnya ditulis PNIA), Pesantren Al-Falah Karangharjo (selanjutnya ditulis PFK), dan Pesantren Annuqayah Guluk-Guluk (selanjutnya ditulis PAG).

\section{Pesantren dan Pemberdayaan Perempuan}

Pesantren yang pada mulanya sebagai lembaga dakwah, pendidikan, dan pemberdayaan masyarakat mengalami perubahan yang cukup signifikan, di mana terjadi optimalisasi fungsi yang semakin kreatif, inovatif, dan produktif dengan tetap berpijak pada nilai-nilai keagamaan Islam. ${ }^{13}$ Artinya, pesantren dapat senantiasa terbuka tetapi tetap selektif terhadap pola-pola perubahan yang ada, termasuk dengan eksistensi perempuan di dalam atau luar pesantren. Hal ini dapat dilihat pada, misalnya, upaya kiai melakukan penguatan konstruksi gender dengan melakukan penafsiran kembali kitab-kitab standar mereka seperti Qurrat al-

10 Eva F. Nisa, "Muslim Women in Contemporary Indonesia: Online Conflicting Narrative Behind the Women Ulama Congress," Asian Studies Review, Vol. 43, No. 3 (2019), 434-454.

11 Gustav Brown, "Conforming Choices: Peer Influence, Adoption, and Interpretation of the Islamic Headscarf in Indonesia," Sociology of Religion, Vol. 80 No. 3 (2019), 372-398.

12 Marhumah, "The Roots of Gender Bias: Misogynist Hadiths in Pesantrens," Indonesian Journal of Islam and Muslim Societies, Vol. 5, No. 2 (2015), 283-304.

13 Ahmad Muhakamurrohman, "Pesantren: Santri, Kiai, dan Tradisi," Ibda': Jurnal Kebudayaan Islam, Vol. 12, No. 2 (2014), 109-118. 
'Uyūn, Uqūd al-Lujayn, dan Adāb al-'Álim wa al-Muta'allim. ${ }^{14}$ Penafsiran tersebut berangkat dari fakta bahwa selama ini perempuan di pesantren dimarginalkan terutama pada aspek peran dan seksualitasnya, ${ }^{15}$ hingga ada suatu usulan agar ada kesepakatan tentang hak dan kewajiban antara pasangan Muslim dalam penikahannya. ${ }^{16}$

Awal mula pesantren mengenal diskursus gender adalah sejak munculnya Perhimpunan Pengembangan Pesantren dan Masyarakat (P3M) yang dikukuhkan pada tahun 1983. Lembaga swadaya masyrakat yang didirikan oleh Masdar F. Mas'udi ini memang sangat konsen dalam penelitian, pelatihan, dan pendidikan dengan tema keperempuanan seperti kesehatan reproduksi dan kesetaraan gender, ${ }^{17}$ di samping juga pemikiran progresif Islam dan pengembangan argumentasi Islam untuk liberalisme serta pluralisme ${ }^{18}$ yang dikenalkan ke masyarakat Islam, dalam hal ini masyarakat NU, menggunakan bahasa-bahasa pesantren. Penulis menilai pola-pola yang dimainkan P3M turut mendorong adanya proses asimilasi pemikiran gender atau pemberdayaan perempuan. Ditambah lagi adanya kiprah kaum elit cendikia yang menamakan dirinya sebagai post-tradisionalisme Islam yang sangat baik dalam hal publikasi gagasan, ${ }^{19}$ sehingga pemikiran-pemikiran gender bisa mendapatkan perhatian kalangan pesantren. Gagasan-gasan tersebut mencoba untuk mengurai ketimpangan sosial melalui keadilan dan kesetaraan gender,

14 Didi Pramono, "The Authority of Kyai Toward the Santri: A Review of Gender Construction at Pondok Pesantren," Komunitas: International Journal of Indonesia Society and Culture, Vol. 10, No. 1 (2018), 92-100.

15 Amanah Nurish, "Women's Same-Sex Relations in Indonesian Pesantren," Gender, Technology and Development, Vol. 14, No. 2 (2010), 267-277.

16 Rachel Rinaldo, "Obedience and Authority among Muslim Couples: Negotiating Gendered Religious Scripts in Contemporary Indonesia," Sociology of Religion, Vol. 80, No. 3 (2019), 323-349.

17 Zuly Qodir, Islam Liberal: Varian-V arian Liberalisme Islam di Indonesia 1991-2002 (Yogyakarta: LKiS, 2010), 274.

18 Budhy Munawar-Rachman, Sekularisme, Liberalisme, dan Pluralisme: Islam Progresif dan Perkembangan Diskursusnya (Jakarta: Grasindo, 2010), 18.

19 Rumadi et al., "Post-Tradisionalisme Islam: Wacana Intelektualisme dalam Komunitas NU," Istiqro': Jurnal Penelitian Islam Indonesia, Vol. 2, No. 1 (2003), 200-227. 
sebagaimana yang disinyalir dalam tulisan Asror. ${ }^{20}$ Dengan bahasa lain, upaya ini dimunculkan untuk merekonstruksi ketimpangan relasi gender yang terbentuk di aras lingkungan pesantren.

Sejak tahun 1994, P3M mengenalkan program pemberdayaan perempuan yang diterjemahkan ke dalam bentuk program-program seperti belajar bersama (halaqah) atau pelatihan. Bahkan, P3M melakukan kerjasama dengan berbagai pesantren seperti Pesantren Annuqayah Guluk-Guluk Madura dalam menguatkan hak-hak reproduksi perempuan. Relasi koorporatif ini akhirnya berhasil meningkatkan penguatan yang masif terhadap kepekaan gender masyarakat pesantren, di mana mulai terdapat variasi orientasi identitas gender hasil konstruksi pesantren tentang hak-hak reproduksi perempuan, seperti sikap moderat kiai secara proporsional, kontekstual, dan interpretatif terhadap kitab-kitab klasik. ${ }^{21}$ Hal tersebut merupakan salah satu wujud nyata tentang bagaimana pesantren meletakkan dasar-dasar pengembangan Islam moderat, sebagaimana yang disimpulkan oleh Ni'am. ${ }^{22}$

Selain P3M, ada pula LSM (Lembaga Swadaya Masyarakat) yang memberikan pengetahuan-pengetahuan baru tentang kesetaraan gender, seperti Puan Amal Hayati dan Rahima. LSM tersebut mendorong perkembangan emansipasi atau penguatan gender di pesantren. Dalam salah satu tulisan Soebahar dideskripsikan bahwa LSM yang dikembangkan oleh Puan Amal Hayati rupanya mampu melakukan gerakan emansipasi dalam proses pengarusutamaan gender (gender mainstreaming). LSM tersebut mampu merespons wacana pemberdayaan perempuan yang kian intens, sehingga menjadikan pesantren sebagai basis gerakan penghapusan kekerasan terhadap perempuan. ${ }^{23}$ Menariknya, Puan Amal Hayati dan jaringan pesantrennya sangat

\footnotetext{
20 Ahidul Asror, "Transformative Propagation of Islamic Boarding School in Response to Contemporary Challenges," Pertanika Journals: Social Science \& Humanities, Vol. 25 (2017), 187-194.

21 Abd. Halim Soebahar dan Hamdanah Utsman, Hak Reproduksi Perempuan dalam Pandangan Kiai (Yogyakarta: Pusat Penelitian Kependudukan UGM, 1999), 46.

22 Syamsun Ni'am, "Pesantren: The Miniature of Moderate Islam in Indonesia," Indonesian Journal of Islam and Muslim Societies, Vol. 5 No. 1 (2015), 111-134.

23 Abd. Halim Soebahar, Pendidikan Islam dan Trend Masa Depan: Pemetaan Wacana dan Reorientasi (Jember: Pena Salsabila, 2009), 115-116.
} 
mendukung diskursus gender terutama pemikiran-pemikiran keperempuanan Sinta Nuriyah Wahid. ${ }^{24}$

Karenanya, LSM tersebut mengupayakan terselenggaranya pendidikan pesantren yang tidak bias gender. Sebab misi mereka membangun pengetahuan dan kesadaran tentang hak-hak perempuan dan masalah gender di komunitas pesantren. Menariknya, proses memasukan pengetahuan kesetaraan gender dalam mindset dan body of knowledge pesantren ternyata mampu membangun kesesuaian dan keselarasan nilai. Nilai-nilai sosial keagamaan kepesantrenan membuka ruang dialogis yang mendorong adanya pemberdayaan perempuan berbasis keagamaan Islam. Ia berjalan secara alami yang dibentuk kesadaran diri pesantren terutama kiai sebagai pengelola, pemimpin, dan pengambil kebijakan. Puan Amal Hayati sendiri aktif melakukan peninjauan ulang secara kontekstual dan berperspektif gender terhadap kitab kuning yang bias gender. Upaya eksplorasi ini, hasilnya disosialisasikan ke pesantren dan masyarakat umum dengan tujuan meminimalisir adanya kekerasan berbasis gender yang bersifat kultural, sosial atau bahkan agama. Percepatan proses rekonstruksi pesantren sebagai basis pemberdayaan perempuan akhirnya tidak bisa terelakkan—atau sudah seharusnya dilakukanoleh pesantren.

Karenanya, pada proses rekonstruksi pesantren gender, pesantren akan menyentuh aspek-aspek substansial seperti kepemimpinan, kurikulum, sistem nilai, atau bahkan juga nilai filosofis. Aspek-aspek ini tidak bisa dilepaskan dari keberadaan pesantren, seperti kepemimpinan kiai, sebagai entitas substansial. Kiai bukan hanya sebagai pengasuh, tetapi ia juga sebagai pemimpin dan pendiri pesantren. Kiai menempati posisi yang sangat sentral mulai gerak, alur, dan pola kelembagaan serta konstruksi keilmuan yang ada di pesantren bahkan dalam bidang politik praktis seperti politik perempuan yang tabu di Indonesia. ${ }^{25}$ Memang perlu diakui bahwa kiprah kiai sangat luas mulai dari

24 Asfa Widiyanto, "Female Religious Authority, Religious Minority and The Ahmadiyyah: The Activism of Sinta Nuryah Wahid," Journal of Indonesian Islam, Vol. 9, No. 1 (2015), 1-24.

25 Ben Hillman, "Increasing Women's Perliamentary Representation in Asia and the Pacific: The Indonesian Experience," Asia \& The Pacific Policy Studies, Vol. 4, No. 1 (2017), 38-49. 
dalam dan luar pesantren, sehingga ada beberapa peneliti seperti Suprayogo mengklasifikasi kiai menjadi empat kategori, yaitu kiai spiritual, kiai advokatif, kiai politik adaptif, dan kiai politik mitra kritis. ${ }^{26}$ Moesa membaginya pada tiga tipologi, yaitu kiai fundamentalis, kiai moderat, dan kiai pragmatis. ${ }^{27}$ Sementara Machmudi menempatkan kiai sebagai cultural brokers. ${ }^{28}$ Karena otoritas yang demikian tinggi itulah akhirnya tidak ada seorang santri yang mampu melawan kiai dalam lingkup pesantren kecuali kiai lain yang lebih tinggi otoritasnya.

Begitu pula, aspek kurikulum merupakan varian integratif dalam pesantren dan menjadi ciri pembeda antara pesantren satu dengan lainnya. Secara umum, kurikulum pesantren tetap memasukkan al-Qur'ān dan Hadīth sebagai bagian inti serta literatur universal dan klasik, yaitu kitab kuning. Oleh karenanya, kurikulum menentukan segala pandangan dan sikap masyarakat pesantren termasuk terhadap perempuan. Adalah hal wajar apabila kurikulum mejadi sasaran yang dipertanyakan apabila diskursus perempuan yang dirumuskan pesantren dipandang bias gender.

Sejauh ini, diklaim bahwa apresiasi kitab kuning terhadap perempuan sangat negatif, bias dan cenderung memarginalkan perempuan. Soebahar dan Utsman mengidentifikasi empat kitab dalam pesantren yang kajiannya cenderung bias gender, yaitu 'Uqüd al-Lujayn karya Shaykh Nawawī Banten, al-Silāḅ fì Bayān al-Nik.ạ. karya Shaykh Muhammad Kholil Bangkalan, Sharh wa Tarjamat 'Uqüd al-Lujayn karya KH. Thoifur Ali Wafa, dan Adäb al-Mar'ah. ${ }^{29}$ Mirisnya lagi, seperti simpulan tulisan Nuroniyah, di dalam pesantren ternyata masih ada pengaruh kultural patriarki yang sulit dihilangkan walaupun telah muncul perubahan. ${ }^{30}$ Bahkan, perempuan diposisikan sebagai perpanjangan tangan laki-laki dalam mengelola pesantren di mana laki-laki menjadi "raja" atau

\footnotetext{
${ }^{26}$ Imam Suprayogo, Kiai dan Politik: Membaca Citra Politik Kyai (Malang: UIN Maliki Press, 2007), 123-125.

27 Ali Maschan Moesa, Nasionalisme Kiai: Konstruksi Sosial Berbasis Agama (Yogyakarta: LKiS, 2005), 281-295.

${ }_{28}$ Machmudi, "Preserving Kyai Authority in Modern Society," Wacana, Vol. 15, No. 2 (2014), 336-350.

${ }^{29}$ Soebahar dan Utsman, Hak Reproduksi Perempuan, 67.

30 Wardah Nuroniyah, "Feminisme dalam Pesantren: Narasi Pemberdayaan Perempuan di Pondok Pesantren Butet Cirebon," Equalita: Jurnal Pusat Studi Gender dan Anak, Vol. 1, No. 1 (2019), 142-164.
} 
pengasuh (kiai). ${ }^{31}$ Oleh karena itu, pentingnya persoalan eksistensi perempuan di pesantren telah mengundang banyak tulisan, seperti tulisan Hafner tentang pembelajaran moral santri perempuan, ${ }^{32}$ tulisan Davies tentang perjuangan hak-hak perempuan, ${ }^{33}$ dan tulisan Hidayah dan Arifi yang fokus pada peran perempuan dalam mengelola pesantren. ${ }^{34}$

Pada konteks rekonstruksi pesantren gender, dua dimensi yang berupa kepemimpinan dan kurikulum tersebut memicu tumbuhkembangnya nilai-nilai filosofis kesetaraan gender. Kepemimpinan dapat dimaknai sebagai subjek pembentuk nilai dalam pesantren, sedangkan kurikulum al-Qur'ān, Hadīth, dan kitab-kitab klasik merupakan sumber ontologi nilai filosofis kesetaraan gender dalam pesantren. Sistem nilai pesantren yang terpisah dari masyarakat mendorong adanya nuansa keunikan berdasarkan kepatuhan harfiah terhadap ajaran agama. Karenanya, nilai filosofis kesetaraan gender di pesantren muncul dari pemaknaan teks-teks al-Qur'ān, Hadìth, dan kitab klasik; ia tidak dilepaskan dari unsur-unsur utama lainnya, yaitu kepemimpinan kiai dan literatur universal. Pembakuan ajaran-ajaran Islam tentang kehidupan sehari-hari bagi kiai dan santri melegitimasikan dua hal, yaitu kitab-kitab sebagai sumber nilai dan kepemimpinan kiai sebagai model implementasinya dalam kehidupan. ${ }^{35}$

Implikasi tatanan tersebut, memunculkan adat, budaya, dan norma sebagai basis pembentukan konstruksi sosial pesantren yang memiliki nuansa kesetaraan gender. Selama ini, adat, budaya, dan norma sering terlihat mendiskreditkan perempuan (misoginis), bahkan konstruksi struktur sosial yang bias gender dijadikan

\footnotetext{
${ }^{31}$ Moh. Rifa'i dan Wardatu Miladiyah, "Agensi Perempuan dalam Manajemen Penddikan Madrasah: Belajar dari Pondok Pesantren Nurul Jadid Probolinggo," Marwah: Jurnal Perempuan, Agama, dan Jender, Vol. 18, No. 1 (2019), 96-106.

32 Claire-Marie Hafner, "On Fun and Freedom: Young Women's Moral Learning in Indonesian Islamic Boarding Schools," Journal of the Royal Anthropological Institute, Vol. 25, No. 3 (2019), 487-505.

33 Sharyn Graham Davies, "Gender and power in Indonesian Islam: Leaders, Feminists, Sufis and Pesantren Selves," Theology \& Sexuality, Vol. 22, No. 1-2 (2017), 128-130.

34 Siti Nur Hidayah dan Ahmad Arifi, "Women in Islamic Education Management: Learning From Pesantren Practices," Ulumuna: Journal of Islamic Studies, Vol. 21, No. 1 (2017), 129-150.

${ }^{35}$ Soebahar, Pendidikan Islam, 119.
} 
instrumen untuk menafsirkan pemahaman teks-teks keagamaan. Akibatnya, lahir pemikiran keagamaan tentang perempuan yang bias gender atau bahkan pemikiran yang cenderung mengeksploitasi diri perempuan. Oleh karena itu, nilai filosofis kesetaraan gender perlu dikonstruksi dengan basis atau prinsip keadilan di pesantren. Aktualitas pesantren dengan sistem tata nilai filosofis inilah akan memberi gambaran utuh (detail) tentang perilaku khas warga pesantren yang bisa berpengaruh terhadap perilaku komunitas sekitar pesantren. Dari rahim pesantren akan lahir nilai kesetaraan gender di tatanan masyarakat, karena sistem nilai filosofis itulah yang memainkan peranan penting membentuk kerangka dasar relasi egaliter atau kesetaraan antara laki-laki dan perempuan.

\section{Rekonstruksi Pesantren Berkesadaran Gender}

Pesantren gender yang dimaksud dalam artikel ini berdimensi sosiologis-teologis, yaitu pesantren yang memiliki kesadaran sosialkeberagamaan yang egaliter dan menggunakan seperangkat ideologi untuk menegakkan relasi non-diskriminatif-subordinatif serta menjauhkan praktik marginalisasi perempuan. Ia berupaya menerobos sekat-sekat doktrinasi patriarkat yang terbentuk serta terlembaga melalui pemahaman dan penafsiran teks-teks keagamaan. Problem "produksi makna" tidak hanya didiskusikan tetapi juga dipraktikkan pada sistem pendidikan pesantren. Oleh karenanya, selain menengakkan kesadaran gender di pesantren, munculnya pesantren gender adalah untuk menepis asumsi negatif yang digeneralisir, seperti tulisan Smith yang berasumsi bahwa pesantren merupakan institusi patriarki yang mengajarkan perempuan menjadi Muslimah yang ideal menurut pemahaman laki-laki. ${ }^{36}$

Pesantren gender mempunyai kultur akademik yang kuat dan demokratis terhadap perkembangan intelektualitas perempuan. Tidak ada refleksi ketakutan laki-laki terhadap perempuan di dalam konteks sosial-akademik atau sosial-keagamaan. Sebaliknya, kaum laki-laki menyadari terjadinya ketimpangan sosial di dalam atau luar pesantren yang salah satu penyebabnya ialah pandangan yang salah terhadap perempuan. PNIA, PFK dan PAG melakukan

\footnotetext{
36 Bianca J. Smith, "Sexual Desire, Piety, and Law in a Javanese Pesantren: Interpreting Varieties of Secret Divorce and Polygamy," Anthropological Forum, Vol. 24, No. 3 (2014), 227-244.
} 
"pembongkaran" terhadap pemahaman dan penafsiran teks-teks keagamaan bias gender yang memunculkan diskursus otoritatifdominatif. Mereka sadar akan adanya ruang ketidakadilan pada pembahasan dan praktik sistem pendidikan pesantren yang bias gender. Salah satu contoh yang dikemukakan, ketika perempuan menjadi pembahasan dalam diskursus teks-teks keagamaan, maka kesejajaran perempuan diukur menggunakan parameter laki-laki. Para elit pesantren seperti kiai, ustaz, atau bahkan nyai dan ustazah pun secara masif melestarikan nilai bias gender dalam sistem pembelajaran pesantren hingga praktik keagamaan. Konten teksteks keagamaan pesntren, terutama kitab kuning seperti kitab fiqh, bersifat diskriminatif dan penuh ketidakadilan. ${ }^{37}$ Sejalan dengan itu, dalam satu tulisannya, Haqqani memberikan solusi agar ada upaya pembacaan ulang terhadap teks-teks al-Qur'ān yang bersifat emansipatoris, sebab al-Qur'ān sendiri merupakan kitab antipatriarkal..$^{38}$

Karenanya, PNIA, PFK, dan PAG membangun nilai filosofis sebagai dasar sistem pendidikan pesantren berkesadaran gender serta menjadi acuan kultur sosial pesantren. Mereka percaya terhadap tiga entitas krusial yang memiliki pengaruh kuat pada kualitas pola pikir masyarakat pesantren, yaitu: agama (beliefs), pengetahuan (knowledge), dan sikap/norma (attitudes). ${ }^{39}$ Tiga entitas ini di tiga pesantren tersebut memiliki relasi yang kuat dan mendasar dalam menopang bangunan nilai filosofis kesadaran gender. PNIA, PFK, dan PAG memiliki kesamaan asumsi. Pola pikir masyarakat pesantren terhadap gender selaras dengan yang mereka peroleh dari proses pembelajaran agama, pengetahuan yang didapatkan, serta norma-norma yang berlaku di lingkungan pesantren. Tiga entitas tersebut secara masif dan sistemik

37 Nurjannah Ismail, "Rekonstruksi Tafsir Perempuan: Membangun Tafsir Berkeadilan Gender (Studi Kritis atas Pemikiran Asghar Ali Engineer, Fatima Mernissi dan Amina Wadud Muhshin tentang Perempuan dalam Islam)," Gender Equality: International Journal of Child and Gender Studies, Vol. 1, No. 1 (2015), 3950.

38 Shehnaz Haqqani, "Women in the Qur'an: An Emancipatory Reading," American Journal of Islamic Social SciencesI, Vol. 35, No. 4 (2018), 68-71.

$39 \mathrm{Hal}$ ini selaras dengan postulasi yang dikembangkan Astin. Nicholas A. Bowman, "Four Critical Years: Effects of College on Beliefs, Attitudes, and Knowledge by Alexander W. Astin (Review)," Journal of College Student Development, Vol. 60, No. 2 (2019), 245-249. 
mempengaruhi pemikiran dan pemahaman masyarakat pesantren tentang kesadaran gender yang difokuskan untuk diaplikasikan pada tata perilaku keseharian mereka. Mereka sadar bahwa pendidikan tidak cukup meningkatkan akses perempuan di ruang publik dan diperlukan faktor lain seperti kesadaran dalam diri perempuan untuk lepas dari belenggu dominatif kultur bias gender. Sonneveld memiliki kesimpulan yang selaras dengan cita tersebut, bahwa pendidikan tidaklah cukup bagi perempuan tanpa faktor lain yang bersifat internal maupun eksternal. ${ }^{40}$

Menariknya, PNIA, PFK, dan PAG berdasarkan kerangka nilai filosofis kesadaran gender mendorong adanya perubahan sistem pendidikan patriarki ke arah pendidikan berbasis gender. Mereka menggabungkan nilai-nilai sosial dan keagamaan yang moderat selama proses perubahan sistem tersebut. Alasan menggunakan sikap keberagamaan moderat disebabkan oleh kerangka dasar pesantren yang merepresentasikan Islam raḥmatan li al-älamin, seakan-akan sikap moderat merupakan nilai yang tidak bisa dipisahkan dari pesantren. ${ }^{41}$ PNIA, PFK, dan PAG berusaha mendinamisasikan sistem pendidikan pesantren agar tidak bias gender. Dalam hal ini, mereka mengorientasikan dan menyiapkan santri perempuan agar juga eksis di masyarakat layaknya laki-laki, terlebih lagi di era disrupsi di mana perempuan terus-menerus menghadapi spesialisasi dalam budaya teknologi. ${ }^{42}$

Keberagamaan yang moderat muncul disebabkan stimulus kepemimpinan kiai PNIA, PFK, dan PAG. Kepemimpinan kiai yang moderat adalah modal sosial yang melahirkan sikap demokratis dan inklusif dalam merespons isu-isu gender, bahkan

40 Nadia Sonneveld, “Women's Access to Legal Education and Their Appointment the Judiciary: The Dutch, Egyptian, and Indonesian Cases Compared," dalam Nadia Sonneveld dan Monika Lindbekk (eds.), Women Judges in the Muslim World: a Comparative Study of Discourse and Practice (Leiden: Brill, 2017), 51-98.

${ }^{41}$ Jeff Ritchey dan Nurhaya Muchtar, "Indonesian Pesantren and Community Social Change: Moderate Islam's Use of Media and Technology as Tools for Community Engagement," Journal of Religion and Popular Culture, Vol. 26, No. 3 (2014), 323-337. Demikian pula, Adamson menyatakan bahwa asimilasi nilai sosial dan keagamaan moderat mampu memperkuat hierarki moral gender. Clarissa Adamson, “Gendered Anxieties: Islam, Women's Rights, and Moral Hierarchy in Java," Anthropolical Quarterly, Vol. 80, No. 1 (2007), 5-37.

42 Mariann Hardey, "Women's Leadership and Gendered Experiences in Tech Cities," Gender in Management, Vol. 34, No. 3 (2019), 188-199. 
tidak jarang pesantren-pesantren tersebut menjadi ajang diskursus dan pergerakan pemberdayaan perempuan. Iklim moderasi inilah yang berpengaruh terhadap kehidupan di PNIA, PFK, PAG, masyarakat sekitarnya serta jaringan pesantren. Pemberdayaan perempuan tersebut terjadi tanpa proses dekonstruksi-revolutif terhadap sistem pesantren. Kiai PNIA, PFK, dan PAG melakukannya secara rekonstruktif-evolutif melalui asimilasi akulturatif sosial-keagamaan. Terlebih lagi PNIA, PFK, dan PAG merupakan lembaga pendidikan Islam berafiliasi pada NU, sehingga sistem nilai yang dikembangkan kiai muncul dari nilai tasämuh, tawäzun, ittidāl, persamaan hak asasi, dan cinta tanah air (ukhuwah islämiyah, ukhuwah watanayah, dan ukbuwah bashariyah). Nilai-nilai ini mendorong tumbuh-kembangnya sikap moderasi bermasyarakat dan beragama.

Kiai PNIA, PFK, dan PAG sendiri memposisikan dirinya sebagai patron bagi santri mereka dengan landasan nilai-nilai keislaman moderat. Muara akhir sikap moderat kiai terletak pada sistem pengajaran dan pendidikan yang menonjolkan pemikiran dinamis dan progresif. Pemikiran pemberdayaan perempuan pun melekat kuat pada sistem pendidikan yang muncul dari gagasangagasan kiai sendiri, sehingga menemukan bentuknya menjadi sistem pendidikan egaliter yang memiliki basis kuat pada nilai-nilai kesetaraan gender. Dari konstruksi pesantren ini akhirnya masyarakat mengklaim PNIA, PFK, dan PAG sebagai pesantren berkesadaran gender, yaitu pesantren yang orientasi sistem pendidikannya menyeimbangkan dan mensejajarkan serta mengangkat harkat martabat perempuan.

Konstruksi pesantren gender tidak lepas dari gagasan-gagasan brilian sosok kiai yang moderat, egaliter dan memiliki sensitifitas gender tinggi. Dengan sensifitas tersebut, seorang kiai mencoba menafsirkan kembali teks-teks klasik untuk melakukan upaya kontekstualisasi terhadap tatanan kehidupan modern, sehingga pemikiran tersebut mempengaruhi kebijakan pendidikan pesantren. Salah satu contoh, PNIA pernah melarang pengajaran kitab 'Uqüd al-Lujayn fì Bayān Huqūq al-Zanjayn karya Shaykh Muhammad Nawawī al-Jāwī al-Bantānī. Sementara itu, PAG memberikan pandangan bahwa munculnya pengetahuan-pengetahuan baru tentang gender mempengaruhi dan melengkapi informasi keagamaan yang akhirnya membantu merekonstruksi kurikulum 
pesantren agar lebih sensitif gender. Mereka sadar jika pemikiranpemikiran dalam kitab klasik perlu dikontekstualisasikan dengan tata kehidupan modern. Duderija mensinyalir bahwa 'urf (tradisi) sangat penting keberadaannya dalam tradisi dan hukum Islam untuk memungkinkan upaya penafsiran teks-teks yang berbasis pada oposisi gender. ${ }^{43}$

Kalangan pesantren menyadari bahwa sistem nilai kepesantrenan yang bias gender akan mempengaruhi atau dipengaruhi nilai masyarakat lokal. Nilai budaya etnik Madura nyatanya secara sosioantropologis mewarnai dan mendominasi sistem nilai pendidikan di PNIA, PFK, dan PAG, atau bahkan sebaliknya. Faktanya, pesantren lebih sering mempengaruhi sistem nilai masyarakat dan mengembangkan "tradisi nilai keislaman." Pesantren lazim melakukan proses ini sebagai bagian dari motif dakwah. ${ }^{44}$ Oleh karenanya, peran determinisme budaya juga terus dilakukan PNIA, PFK, dan PAG untuk mempertahankan serta mengembangkansistem pendidikan agar lebih humanis dan egaliter.

Berdasarkan sikap pesantren yang asimilatif-akulturatif, bisa dikatakan bahwa sistem nilai yang dikembangkan PNIA, PFK, dan PAG melalui basis sistem nilai keagamaan serta budaya tersebut sama sekali tidak mencerminkan sistem nilai tradisional-feodalistik yang anti perubahan. Sebaliknya, sistem nilai yang dikembangkan relatif adaptif dengan perubahan, termasuk dengan informasiinformasi baru aspek sosial-budaya, sains, teknologi, dan lain sebagainya. Ia juga melakukan akulturasi rekonstruktif terhadap nilai-nilai baru seperti nilai gender melalui upaya memunculkan perspektif baru pesantren untuk menafsirkan teks-teks keagamaan. Keragaman yang ada di pesantren dikelola sebagai kekayaan, bukan didorong untuk memunculkan pertikaian seperti yang didegungkan oleh akademisi agama di seluruh dunia. ${ }^{45}$ Adalah hal yang masuk

\footnotetext{
43 Adis Duderija, "The Custom ('Urf) Based Assumptions Regarding Gender Roles and Norms in the Islamic Tradition: A Critical Examination," Studies in Religion/Sciences Religieuses, Vol. 45, No. 4 (2016), 581-599.

44 Yanwar Pribadi, "Pesantren Pluralis: Peran Pesantren Ngalah dalam Mengembangkan Nilai-Nilai Pluralisme di Tengah Masyarakat yang Multikultural by M. Muntahibun Nafis," Journal of the Humanities and Social, Vol. 174, No. 2-3 (2018), 333-337.

${ }^{45}$ Lihat detailnya dalam Anindita N. Balslev (ed.), On World Religions: Diversity, Not Dissension (California: SAGE Publications, 2014).
} 
akal jika PNIA, PFK, dan PAG pada saat ini dikenal menjadi pesantren yang berbasis pemberdayaan perempuan.

Tampaknya, kesadaran gender semacam ini justru lebih banyak muncul di pesantren yang berada pada basis masyarakat agraris (pedesaan). PNIA dan PFK berada di desa yang transisional dari budaya tradisional ke modern, sedangkan PAG berada di pusat msyarakat agraris. Walaupun demikian, ketiga pesantren ini memiliki pola perbedaan signifikan pada beberapa bagian. Pertama, sejak berdirinya, PNIA telah menapak pada tangga pesantren modern, sedangkan PFK dan PAG berevolusi dari pesantren tradisional (salaf) ke modern (khalaf). Kedua, budaya santri di PNIA terbilang heterogenistik (budaya Jawa dan Madura), sedangkan di PFK dan PAG lebih homogen (hanya budaya Madura). Ketiga, secara latar pendidikan kepemimpinan, kiai di PNIA memiliki latar belakang pendidikan tradisional (salaf) dengan kepemimpinan tunggal, sementara kiai di PFK dan PAG sendiri mempunyai pendidikan tradisional (salaf) sekaligus modern (khalaf) dengan pola kepemimpinan kolektif. Terlepas dari beberapa perbedaan di atas, ketiga pesantren ini terus berbenah melalui rekonseptualisasi sistem dari pendidikan yang bias gender ke pendidikan yang egaliter dan memberdayakan perempuan.

\section{Landasan Filosofis Pendidikan Pesantren Berkesadaran Gender}

PNIA, PFK, dan PAG pada konteks ini melakukan upaya pemberdayaan perempuan melalui sistem pendidikan egaliter berbasis nilai-nilai keagamaan. PNIA, PFK, dan PAG menafsirkan kembali teks-teks keagamaan (al-Qur'ān, al-Ḥadìth), terutama konstruksi pemikiran ulama salaf dalam kitab kuning. Mereka berusaha mencari arah "tujuan" melalui upaya yang aksidental dan transformatif agar bisa menampilkan penafsiran yang legitimated. Konstruksi penafsiran yang terkodifikasi dalam kitab-kitab klasik dianggap sebagai pengertian historis relatif.

Transformasi situasi dan kondisi masyarakat disimpulkan memerlukan pembacaan ulang yang didasarkan pada landasan aksiologis shari' ${ }^{-6}$ h Islam. PNIA, PFK, dan PAG berusaha untuk mengungkap "pesan suci" dan rigid dalam teks-teks keagamaan, sehingga mereka mengajukan pertanyaan kritis dan esensial terkait perempuan serta hukum yang mengitari. Bahkan, pertanyaanpertanyaan mereka telah dikondisikan secara sosiologis, psikologis, 
politis, dan intelektualis. Pertanyaan-pertanyaan mereka relatif cenderung segar dan melahirkan pertanyaan-pertanyaan baru yang lebih kritis. Hal ini bermakna bahwa "substansi" Islam bukan ketentuan abadi, tetapi ia ada secara konstan melalui upaya penafsiran, tulisan yang berulang-ulang sesuai spirit transformasi sosial, dan perkembangan kesadaran manusia. Mereka senantiasa mengaitkan etika sosiologis dengan nilai teologis, sehingga rasionalitas bergerak bebas tanpa ada batasan-batasan yang mengisolasi antara dimensi profan dan transendental. Upaya atau perilaku ini dikatakan sebagai etika moderasi (wasatiyab), sehingga ia menjadi agen etis dalam mengejar komunitas yang adil. ${ }^{46}$

Kesatuan aksiologis tersebut yang memunculkan kesadaran gender di lingkungan pesantren. Seluruh persoalan perempuan akhirnya juga memproduksi kesadaran ilmiah atas makna teks-teks keagamaan yang bias gender. Pada ranah ini, kiai sebagai "corong kesadaran" di PNIA, PFK, dan PAG tidak mau terjebak pada kesalahan epistemologis yang memisahkan pengetahuan keagamaan dengan pengetahuan duniawi. Jika kesalahan ini terjadi, maka muncul kesenjangan hingga pada titik kontradiksi antara teks-teks keagamaan sebagai "yang sakral" dan realitas gender "yang profan," dan kekhawatirran akan adanya upaya "penundukan" secara dominatif terhadap realitas gender dengan mengatasnamakan teks-teks keagaman "yang sakral." Pola ini sejatinya telah dipraktikkan oleh gerakan Islam transnasional yang mengusung ideologi Salafi dalam dunia pendidikan Islam, di mana mereka mengunggulkan penafsiran skriptual di atas realitas sosial atau pada dimensi gerakan purifikasi keagamaan. ${ }^{47}$

Pola dialektis antarteks keagamaan (terutama al-Qur'ān dan alHadìth) memberikan ruang dinamis bagi PNIA, PFK, dan PAG untuk mengurai konstruksi sistem pendidikan pesantren yang bias gender. PNIA, PFK, dan PAG sadar bahwa problematika sistem pendidikan pesantren yang bias gender merupakan masalah sosial

\footnotetext{
46 Etin Anwar, "The Ethics of Wasatiyah and the Pursuit of Gender Equality," American Journal of Islamic Social Sciences, Vol. 32, No. 4 (2015), 47-65.

47 Toto Suharto, "Transnational Islam Education in Indonesia: An Ideological Perspective," Contemporary Islam, Vol. 12, No. 2 (2018), 101-122; Joas Wagemakers, "Salafism's Historical Continuity: The Reception of 'Modernist' Salafis By 'Purist' Salafis in Jordan," Journal of Islamic Studies, Vol. 30, No. 2 (2019), 205-231.
} 
kemanusiaan dan terintegrasi dengan masalah laki-laki. Tragisnya, masalah tersebut dikemas secara normatif dengan teks-teks keagamaan sehingga seperti "realitas yang bersifat rigid dan kodrati." Oleh karena ittu, PNIA, PFK, dan PAG mengedepankan moralitas kesatuan kemanusiaan sebagai landasan filosofis sistem pendidikan egaliter, yang salah satunya diandai dengan upaya penafsiran kembali teks-teks keagamaan yang bias gender untuk mengungkap dominasi manipulatif.

Dinamika yang menarik adalah tiga pesantren tersebut merasa tidak cukup menyatakan Islam sebagai "agama yang ramah perempuan" atau "agama egaliter." Mereka cenderung menerobos sekat-sekat yang tabu dalam dunia pesantren. Di PNIA, olahraga yang khusus santi laki-laki, seperti sepak takraw dan bola volly, juga dimainkan oleh santri perempuan. Namun demikian, mereka teguh berpegang pada wahyu serta tetap mengikat diri mereka pada sunnah kenabian dan al-khulafä al-räshidìn. Karenanya, dinamika pesantren turut mewarnai kesuksesan asimilasi nilai teks-teks keagamaan dengan realitas sosial-budaya. Tidak heran jika Bull sejak awal telah menyakini adanya potensi dinamis dalam diri pesantren. Menurutnya, jika masyarakat berubah, maka pesantren turut berubah. ${ }^{48}$

Ketiga pesantren tersebut dapat dikatakan memiliki misi yang sama, yaitu pemikiran transformatif untuk menyejajarkan relasi laki-laki dan perempuan. Mereka memperlebar epistemologi keilmuan pesantren menuju pemikiran bayān (teks), burbānì (rasionalitas-empiris), dan 'irfānì (intuitif). Di saat permasalahan etis dan metodologis muncul pada saat asimilasi-akulturasi kesadaran gender ke dalam sistem pendidikan pesantren, mereka mampu mengantisipasi dengan adanya kesadaran filosofis dan teologis yang terpatri dalam tradisi keilmuan pesantren. Kesadaran filosofis melahirkan metodologi keilmuan pendidikan pesantren yang berkesadaran gender, sedangkan kesadaran teologis memunculkan etika monoteistik. Karenanya, tiga pesantren tersebut menyadari bahwa tradisi bias gender merupakan tradisi asing di luar etika Islam dan datang dari kesalahan pembacaan masyarakat terhadap teks al-Qur'ān dan Hadīth. Antara wahyu dan rasionalitas tidak

\footnotetext{
48 Ronald A. Lukens-Bull, "Two Sides of the Same Coin: Modernity and Tradition in Islamic Education in Indonesia," Anthropology \& Education Quarterly, Vol. 32, No. 3 (2001), 350-372.
} 
akan terjadi kontradiksi ketika berbicara kebenaran, seperti yang dikatakan oleh Ibn Rushd. ${ }^{49}$

Solusi yang dikembangkan PNIA, PFK, dan PAG untuk memberdayakan perempuan adalah melalui upaya restrukturisasi pengajaran kitab kuning dan peninjauan kembali "pesan" yang ada di dalamnya. Surah al-Hujurāt ayat 13 menjadi dasar bagi mereka untuk mentransformasi orientasi sistem pendidikan pesantren bias gender ke egaliter, sehingga dalam konteks interaksi sosial di pesantren, setiap individu mempunyai kedudukan sejajar dengan lainnya, dan statusnya tidak dibedakan berdasarkan kesukuan, ras, atau bahkan jenis kelamin. Sistem pendidikan egaliter mengemas kesadaran gender sesuai dengan pesan suci Islam yang hanya membedakan manusia berdasarkan derajat ketakwaan, bukan lainnya. Implikasinya, hak-hak minoritas perlu diangkat sebagai konsensus tentang demokrasi sistem pendidikan pesantren.

Hal tersebut bisa dikatakan sebagai orientasi kesatuan ontologis yang telah tersurat dalam al-Nisā' ayat 1. Laki-laki dan perempuan memiliki hak dan kewajiban yang sama. Jiwa mereka merupakan realitas spiritual yang tercermin dalam bentuk tubuh, seperti yang dikatakan Thomas Aquinas. ${ }^{50}$ Dengan demikian, adalah sebuah keniscayaan bagi pesantren untuk membuka krankran demokrasi agar perempuan bisa memiliki ruang bereksistensi. Laki-laki dan perempuan secara defensif harus bisa bersama-sama saling mengangkat derajat martabat mereka, seperti yang dilakukan The Chastity Society di Yordania. ${ }^{51}$ Tumbuh kembangnya sikap toleransi memang perlu dimulai dari ranah sikap demokratif. ${ }^{52}$ Konstruksi filosofis pendidikan egaliter sangat menentukan rekonstruksi pesantren berkesadaran gender, terutama dalam hal ini untuk memberdayakan perempuan.

\footnotetext{
49 Francisco J. Romero Carrasquillo, "Philosophy and the Metaphorical Interpretation of Religious Texts in Averroes, Maimonides, and Aquinas," The Muslim World, Vol. 109, No. 4 (2019), 627-647.

50 John Finley, "Man more Animal than Anything: The Unity in Human Agency," New Blackfriars, Vol. 100, No. 1090 (2019), 677-697.

51 Geoffrey Fitzgibbon Hughes, "The Chastity Society: Disciplining Muslim Men," Journal of the Royal Anthropological Institute, Vol. 23, No. 2 (2017), 267-284.

52 Saiful Mujani, "Explaining Religio-Political Tolerance Among Muslims: Evidence from Indonesia," Studia Islamika, Vol. 26, No. 2 (2019), 319-351.
} 


\section{Penutup}

Akhirnya, secara holistik, rekonstruksi tiga pesantren di Jawa Timur, yaitu PNIA, PFK, dan PAG memiliki kekhasan. Ketiga pesantren tersebut melakukan rekonstruksi pesantren berkesadaran gender sebagai basis pemberdayaan perempuan. Rekonstruksi tersebut terutama terlihat dari pola kepemimpinan kiai dan kurikulum pesantren yang terus dikaji ulang sehingga selaras dengan transformasi sosial tanpa melepaskan diri dari ikatan "substansi" Islam. Namun demikian, meskipun proses rekonstruksi pesantren berasal dari dalam dan luar sistem pesantren, tetapi adaptasi kreativitas inovatif dan diseminasinya sangat tergantung pada sosok dan otoritas kiai sebagai pengasuh, di mana otoritas tersebut bisa berpola the single authority sebagaimana di PNIA dan PFK, dan the collective authority di PAG. Dikarenakan pengaruh otoritas kiai tersebut sangat dominan, maka kesadaran kiai terhadap gender menjadi landasan pokok keberhasilan proses pemberdayaan perempuan melalui pesantren.

\section{Daftar Rujukan}

Adamson, Clarissa. "Gendered Anxieties: Islam, Women's Rights, and Moral Hierarchy in Java," Anthropolical Quarterly, Vol. 80, No. 1, 2007.

Agusti et al. "The Role of Islamic Boarding School on the Economic Empowerment of the Society: a Case Study at Islamic Boarding School Salafiyah Syafi'iyah Banyuputih Situbondo," International Journal of Research in Humanities and Social Studies, Vol. 6, No. 3, 2019.

Anna M. Gade. "Tradition and Sentiment in Indonesian Environmental Islam," Worldviews: Global Religions, Culture, and Ecology, Vol. 16, No. 3, 2012.

Anwar, Etin. "The Ethics of Wasatiyah and the Pursuit of Gender Equality," American Journal of Islamic Social Sciences, Vol. 32, No. 4, 2015.

Arif, Mahmud. "Multiculturalism of Pesantren Kyai: A Study of Kyai's Perspective on Multicultural Issues and Their Actualization at Pesantren Sunni Darussalam and al-Imdad Yogyakarta Indonesia," International Journal of Education and Research, Vol. 4 No. 10, 2016. 
Arnez, Monika. "Empowering Women Through Islam: Fatayat NU Between Tradition and Change," Journal of Islamic Studies, Vol. 21, No. 1, 2010.

Asror, Ahidul. "Transformative Propagation of Islamic Boarding School in Response to Contemporary Challenges," Pertanika Journals: Social Science \& Humanities, Vol. 25, 2017.

Balslev, Anindita N. (ed.). On World Religions: Diversity, Not Dissension. California: SAGE Publications, 2014.

Bawani, Imam et al. Pesantren Buruh Pabrik: Pemberdayaan Burub Pabrik Berbasis Pendidikan Pesantren. Yogyakarta: LKiS, 2011.

Bowman, Nicholas A. "Four Critical Years: Effects of College on Beliefs, Attitudes, and Knowledge by Alexander W. Astin," Journal of College Student Development, Vol. 60, No. 2, 2019.

Brown, Gustav. "Conforming Choices: Peer Influence, Adoption, and Interpretation of the Islamic Headscarf in Indonesia," Sociology of Religion, Vol. 80 No. 3, 2019.

Bull, Ronald A. Lukens. "Two Sides of the Same Coin: Modernity and Tradition in Islamic Education in Indonesia," Anthropology \& Education Quarterly, Vol. 32, No. 3, 20011

Carrasquillo, Francisco J. Romero. "Philosophy and the Metaphorical Interpretation of Religious Texts in Averroes, Maimonides, and Aquinas," The Muslim World, Vol. 109, No. 4, 2019.

Davies, Sharyn Graham. "Gender and power in Indonesian Islam: Leaders, Feminists, Sufis and Pesantren Selves," Theology \& Sexuality, Vol. 22, No. 1-2, 2017.

Duderija, Adis. "The Custom ('Urf) Based Assumptions Regarding Gender Roles and Norms in the Islamic Tradition: A Critical Examination," Studies in Religion/Sciences Religieuses, Vol. 45, No. 4, 2016.

Fanani, Abdl. Chayyi. Pesantren Anak Jalanan. Surabaya: Alpha, 2008.

Finley, John. "Man more Animal than Anything: The Unity in Human Agency," New Blackefriars, Vol. 100, No. 1090, 2019.

Hafner, Claire-Marie. "Model of Achievement: Muslim Girls and Religious Authority in a Modernist Islamic Boarding School In Indonesia," Asian Studies Review, Vol. 40, No. 4, 2016. 
----. "On Fun and Freedom: Young Women's Moral Learning in Indonesian Islamic Boarding Schools," Journal of the Royal Anthropological Institute, Vol. 25, No. 3, 2019.

Halim, Wahyuddin. "Young Islamic Preachers on Facebook: Pesantren As'adiyah and its Engagement with Social Media," Indonesia and The Malay World, Vol. 46, No. 134, 2018.

Haqqani, Shehnaz. "Women in the Qur'an: An Emancipatory Reading," American Journal of Islamic Social SciencesI, Vol. 35, No. 4, 2018.

Hardey, Mariann. "Women's Leadership and Gendered Experiences in Tech Cities," Gender in Management, Vol. 34, No. 3, 2019.

Hidayah, Siti Nur dan Ahmad Arifi. "Women in Islamic Education Management: Learning From Pesantren Practices," Ulumuna: Journal of Islamic Studies, Vol. 21, No. 1, 2017.

Hillman, Ben. "Increasing Women's Perliamentary Representation in Asia and the Pacific: The Indonesian Experience," Asia \& The Pacific Policy Studies, Vol. 4, No. 1, 2017.

Hoon, Chang-Yau. "Putting Religion into Multiculturalism: Conceptualising Religious Multiculturalism in Indonesia," Asian Studies Review, Vol. 41, No. 3, 2017.

Hughes, Geoffrey Fitzgibbon. "The Chastity Society: Disciplining Muslim Men," Journal of the Royal Anthropological Institute, Vol. 23, No. 2, 2017.

Indra, Hasbi. "Pesantren and Entrepreneurship Education," Edukasi: Jurnal Penelitian Pendidikan Agama dan Keagamaan, Vol. 17, No. 2, 2019.

Ismah, Nor. "Destabilising Male Domination: Building Community-Based Authority among Indonesia Female Ulama," Asian Studies Review, Vol. 40, No. 4, 2017.

Ismail, Nurjannah. "Rekonstruksi Tafsir Perempuan: Membangun Tafsir Berkeadilan Gender (Studi Kritis atas Pemikiran Asghar Ali Engineer, Fatima Mernissi dan Amina Wadud Muhshin tentang Perempuan dalam Islam)," Gender Equality: International Journal of Child and Gender Studies, Vol. 1, No. 1, 2015.

Khojir. "The Pesantren Network in Samarinda," Jurnal Pendidikan Islam, Vol. 5, No. 2, 2016.

Machmudi. "Preserving Kyai Authority in Modern Society," Wacana, Vol. 15, No. 2, 2014. 
Marhumah. "The Roots of Gender Bias: Misogynist Hadiths in Pesantrens," Indonesian Journal of Islam and Muslim Societies, Vol. 5, No. 2, 2015.

Mas'ud, Ali et al. "Evolution and Orientation of Islamic Education in Indonesia and Malaysia", Journal of Indonesian Islam, Vol. 13, No. 1, 2019.

Moesa, Ali Maschan. Nasionalisme Kiai: Konstruksi Sosial Berbasis Agama. Yogyakarta: LKiS, 2005.

Muazza et al. "Education in Indonesia Islamic Boarding Schools: Voices on Curriculum and Radicalism, Teacher, and Facilities," The Islamic Quarterly, Vol. 62, No. 4, 2018.

Muhakamurrohman, Ahmad. "Pesantren: Santri, Kiai, dan Tradisi," Ibda': Jurnal Kebudayaan Islam, Vol. 12, No. 2, 2014.

Mujani, Saiful. "Explaining Religio-Political Tolerance Among Muslims: Evidence from Indonesia," Studia Islamika, Vol. 26, No. 2, 2019.

Mukaffa, Zumrotul. "Madrasah Diniyah Sebagai Pola Diseminasi Islam Moderat di Pesantren Mahasiswa Darussalam Keputih Surabaya," Jurnal Pendidikan Agama Islam, Vol. 6, No. 1, 2018.

Ni'am, Syamsun. "Pesantren: The Miniature of Moderate Islam in Indonesia," Indonesian Journal of Islam and Muslim Societies, Vol. 5 No. 1, 2015.

Nisa, Eva F. "Muslim Women in Contemporary Indonesia: Online Conflicting Narrative Behind the Women Ulama Congress," Asian Studies Review, Vol. 43, No. 3, 2019.

Nurish, Amanah. "Women's Same-Sex Relations in Indonesian Pesantren," Gender, Technology and Development, Vol. 14, No. 2, 2010 .

Nuroniyah, Wardah. "Feminisme dalam Pesantren: Narasi Pemberdayaan Perempuan di Pondok Pesantren Butet Cirebon," Equalita: Jurnal Pusat Studi Gender dan Anak, Vol. 1, No. 1, 2019.

Pohl, Florian. Islamic Education and the Public Sphere: Today's Pesantren in Indonesia. New York: Waxmann, 2009.

Pramono, Didi. "The Authority of Kyai Toward the Santri: A Review of Gender Construction at Pondok Pesantren," Komunitas: International Journal of Indonesia Society and Culture, Vol. 10, No. 1, 2018. 
Pribadi, Yanwar. "Kiai in Madura: Their Roles in Local Politics in Indonesia," American Journal of Islamic Social Sciences, Vol. 29, No. 3, 2012.

----. "Pesantren Pluralis: Peran Pesantren Ngalah dalam Mengembangkan Nilai-Nilai Pluralisme di Tengah Masyarakat yang Multikultural by M. Muntahibun Nafis," Journal of the Humanities and Social, Vol. 174, No. 2-3, 2018.

Qodir, Zuly. Islam Liberal: Varian-Varian Liberalisme Islam di Indonesia 1991-2002.bYogyakarta: LKiS, 2010.

Rachman, Budhy Munawar. Sekularisme, Liberalisme, dan Pluralisme: Islam Progresif dan Perkembangan Diskursusnya. Jakarta: Grasindo, 2010.

Rahmat, Munawar. "Kiai Hasan Ulama Mursyid Tarekat Shaththariah As a Pioneer of Modern Pesantren," Jurnal Pendidikan Islam, Vol. 7, No. 1, 2018.

Rifa'i, Moh. dan Wardatu Miladiyah. "Agensi Perempuan dalam Manajemen Penddikan Madrasah: Belajar dari Pondok Pesantren Nurul Jadid Probolinggo," Marwab: Jurnal Perempuan, Agama, dan Jender, Vol. 18, No. 1, 2019.

Rinaldo, Rachel. "Obedience and Authority among Muslim Couples: Negotiating Gendered Religious Scripts in Contemporary Indonesia," Sociology of Religion, Vol. 80, No. 3, 2019.

Ritchey, Jeff dan Nurhaya Muchtar. "Indonesian Pesantren and Community Social Change: Moderate Islam's Use of Media and Technology as Tools for Community Engagement," Journal of Religion and Popular Culture, Vol. 26, No. 3, 2014.

Rumadi et al. "Post-Tradisionalisme Islam: Wacana Intelektualisme dalam Komunitas NU," Istiqro': Jurnal Penelitian Islam Indonesia, Vol. 2, No. 1, 2003.

Saepudin, Juju. "Pesantren Darut Taubah dan Pekerja Seks Komersial Saritem Kota Bandung," Analisa: Journal of Social Science and Religion, Vol. 22, No. 2, 2015.

Sirry, Mun'im. "The Public Expression of Traditional Islam: The Pesantren and Civil Society in Post-Suharto Indonesia," The Muslim World, Vol. 100, No. 1, 2010.

Smith, Bianca J. "Sexual Desire, Piety, and Law in a Javanese Pesantren: Interpreting Varieties of Secret Divorce and Polygamy," Anthropological Forum, Vol. 24, No. 3, 2014. 
Soebahar, Abd. Halim dan Hamdanah Utsman. Hak Reproduksi Perempuan dalam Pandangan Kiai. Yogyakarta: Pusat Penelitian Kependudukan UGM, 1999.

Soebahar, Abd. Halim. "Pesantren Gender: Konstruksi Baru Basis Pemberdayaan Perempuan," al-'Adalab: Jurnal Kajian Keislaman dan Kemasyarakatan, Vol. 5, No. 2, 2002.

-----. Pendidikan Islam dan Trend Masa Depan: Pemetaan Wacana dan Reorientasi. Jember: Pena Salsabila, 2009.

Sonneveld, Nadia. “Women's Access to Legal Education and Their Appointment the Judiciary: The Dutch, Egyptian, and Indonesian Cases Compared," dalam Nadia Sonneveld dan Monika Lindbekk (eds.), Women Judges in the Muslim World: a Comparative Study of Discourse and Practice. Leiden: Brill, 2017.

Srimulyani, Eka. "Muslim Women and Education in Indonesia:

The Pondok Pesantren Experience," Asia Pacific Journal of Education, Vol. 27, No. 1, 2007.

Suharto, Toto. "Transnational Islam Education in Indonesia: An Ideological Perspective," Contemporary Islam, Vol. 12, No. 2, 2018.

Suprayogo, Imam. Kiai dan Politik: Membaca Citra Politik Kyai. Malang: UIN Maliki Press, 2007.

Wagemakers, Joas. "Salafism's Historical Continuity: The Reception of 'Modernist' Salafis By 'Purist' Salafis in Jordan," Journal of Islamic Studies, Vol. 30, No. 2, 2019.

Widiyanto, Asfa. "Female Religious Authority, Religious Minority and The Ahmadiyyah: The Activism of Sinta Nuryah Wahid," Journal of Indonesian Islam, Vol. 9, No. 1, 2015. 